\title{
Continuous Subcutaneous Insulin Infusion: Good Blood Glucose Control for up to 4 Days
}

\author{
J. C. Pickup ${ }^{1}$, H. Keen ${ }^{1}$, J. A. Parsons ${ }^{2}$, and K. G. M. M. Alberti ${ }^{3}$ \\ ${ }^{1}$ Unit for Metabolic Medicine, Guy's Hospital Medical School, London, ${ }^{2}$ Laboratory for Endocrine Physiology and Pharmacology, \\ National Institute for Medical Research, Mill Hill, London, and ${ }^{3}$ Department of Clinical Biochemistry, Royal Victoria Infirmary, \\ Newcastle-upon-Tyne, England
}

\begin{abstract}
Summary. Six insulin-dependent diabetics were studied on their conventional insulin treatment and during continuous, dual-rate, subcutaneous insulin infusion for periods of up to 4 days. Diabetic control, as assessed by mean plasma glucose, range of plasma glucose values, $\mathbf{M}$-value or range of $\mathbf{M}$-values was improved significantly in 5 patients (mean \pm SD plasma glucose concentration on final infusion day $6.9 \pm 1.3 \mathrm{mmol} / \mathrm{l}$, versus $11.3 \pm 3.2 \mathrm{mmol} / 1$ on conventional treatment). Once a suitable insulin dose was established blood glucose control could be maintained by continuous subcutaneous insulin infusion using the same daily infusion rate without frequent adjustment. In some cases this was less than the daily dose on the conventional treatment. However, glycaemic control in one "brittle" diabetic, with unpredictable swings in blood glucose on her normal regimen, was not improved by continuous subcutaneous insulin infusion. During the period tested there was no sepsis at the cannula implantation site and patients did not find the system uncomfortable or unduly inconvenient.
\end{abstract}

Key words: Subcutaneous insulin infusion, near-normoglycaemia, diabetic control, open-loop device.

There is increasing evidence from studies in man and animals to suggest that good blood glucose control in diabetes decreases the risk of development of late complications, in particular, microangiopathy $[1,2]$. Although the link between diabetic control and complications is still controversial [3-5] various methods of improving metabolic control are currently being investigated.

Glycaemia-controlled insulin infusion devices (artificial pancreases) have been extremely successful in achieving short-term normoglycaemia [6] but the use of such systems is limited in the long term by the bulk, cost, complexity and, most importantly, by the intravenous infusion route. This latter point also applies to more portable intravenous insulin infusion devices without glucose sensing and servo-control [7-10].

Early studies have shown that improvement in blood glucose and other intermediary metabolites can be achieved in some insulin-dependent, diabetic patients over 24 hour periods using continuous, $s u b$ cutaneous insulin infusion (CSII) from a dual-rate, portable battery-driven syringe pump [11-13]. To investigate the feasibility of CSII in longer-term management of diabetic patients we have studied initially the use of this system in achieving good control for up to 4 days.

\section{Patients and Methods}

\section{Continuous Subcutaneous Insulin Infusion System}

The principle has been described previously [11]. In these longerterm studies, however, we used a specially adapted version of a current production model of the Mill Hill Infuser (Muirhead Ltd., Beckenham, Kent, U.K.) rather than the prototype used in the pilot study. The infuser is a portable, battery-driven syringe pump [14] measuring $114 \times 72 \times 23 \mathrm{~mm}$ and weighs about $300 \mathrm{~g}$. It was fitted with $3 \mathrm{ml}$ disposable plastic syringes with Luer locks.

Each infuser was specially constructed to deliver at 2 rates, a basal rate of $40-50 \mu \mathrm{l} / \mathrm{h}$ (exact rate depending on the setting of the individual pump) and an 8-fold higher rate for meals. The high rate was achieved electronically by pressing a small guarded button on the side of the pump, the rate automatically returning to the basal level after $17 \mathrm{~min}$. A button on the inside of the syringe compartment cancels the high rate in emergencies. A light-emitting diode and a faint motor surge-hum signal normal operation of the infuser. Figure 1 shows one of the pumps used.

The procedure for inserting the fine nylon cannulae (Portex Ltd., Hythe, Kent, U.K.) in the right subcostal region of the anterior abdominal wall has been previously described [12]. 


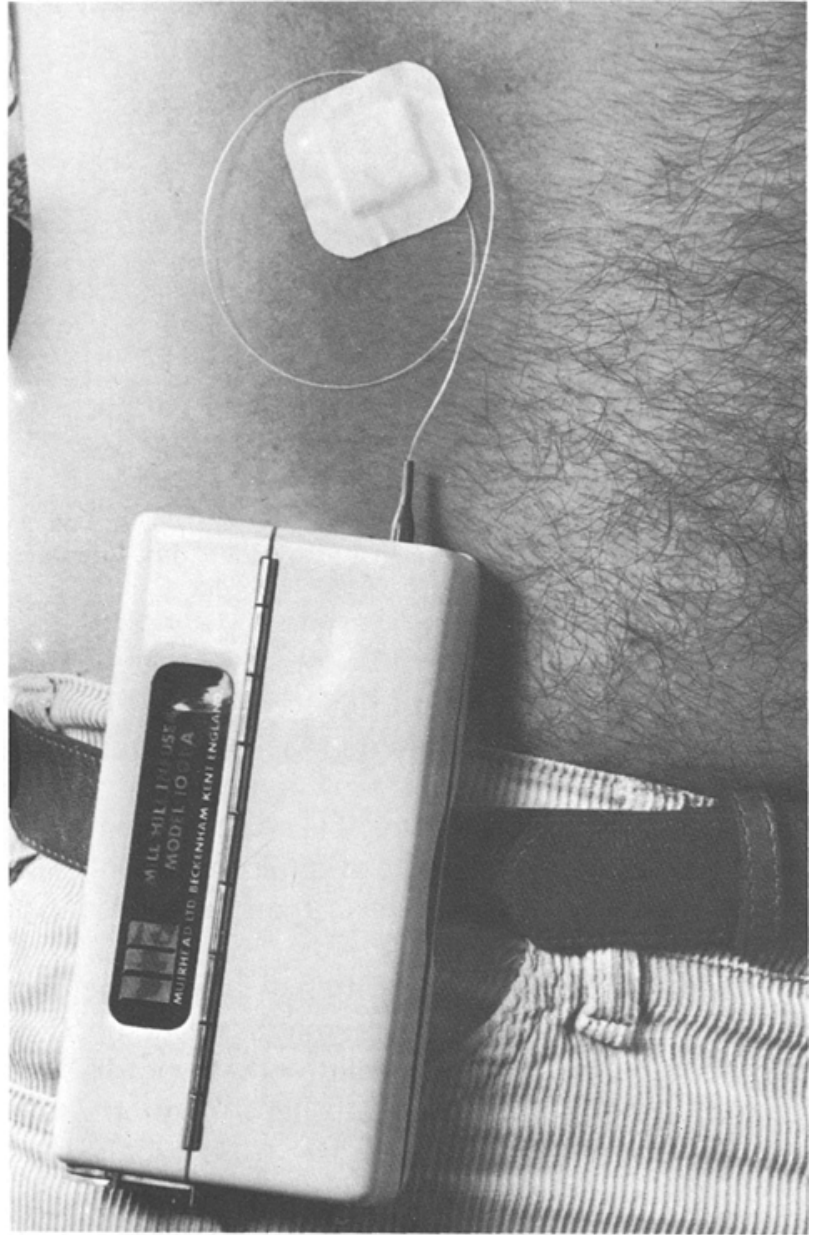

Fig. 1. The specially adapted dual-rate, Mill Hill Infuser, shown fitted to a patient. Insulin is delivered from the syringe pump via the fine nylon cannula, which is seen subcutaneously implanted in the anterior abdominal wall
Actrapid monocomponent insulin (Novo Industri) was infused diluted as necessary for each patient (see below) with $0.154 \mathrm{mmol} /$ 1 sterile saline. The minimum insulin concentration was $29 \mathrm{U} / \mathrm{ml}$.

\section{Patients and Protocol}

Six insulin-dependent patients who fully understood and agreed to the experimental nature of the study were recruited. Their clinical characteristics are shown in Table 1 . The patients were admitted to a Metabolic Ward. Plasma glucose was closely monitored whilst the patients were receiving their usual subcutaneous depot injection treatment on venous blood obtained from an indwelling Teflon cannula at least every hour during the day and every 2 hours at night. Glucose was measured by the glucose oxidase method adapted for an autoanalyser or by an Analox GM5 automatic glucose analyser.

Patients received a standard breakfast [12] containing $50 \mathrm{~g}$ of carbohydrate (energy content $1.7 \mathrm{MJ}$ ) but the remainder of the meals were according to their previously prescribed diet.

On a subsequent day subcutaneous infusion was started, beginning in the evening, so that an overnight "run-in" period would bring the blood glucose into approximately the normal range.

The degree of control on the conventional treatment was used as a basis for an initial estimate of the infusion dose. Generally, the usual total daily dose was used on the first CSII day. If there was hyperglycaemia on this first day, the dose was increased in roughly $20-25 \%$ steps or decreased by this amount if there was hypoglycaemia. This process was repeated daily until stable control was achieved.

The insulin dose infused on the final day is shown in Table 1 as a percentage of the daily dose on conventional treatment. The range of basal infusion rates was $1.2-1.8 \mathrm{U} / \mathrm{h}$ (total volume infused was approximately $1.35 \mathrm{ml} /$ day). The pump was switched to high rate $30 \mathrm{~min}$ before breakfast, lunch and evening meal but not before mid-morning, mid-afternoon or late-night snacks. In some patients better control was obtained by engaging the high rate for twice as long (i. e. $34 \mathrm{~min}$ ) before breakfast (patients 2 and 4).

Blood was withdrawn for analysis and food given as on the conventional treatment day. Physical activity was designed to be comparable on the infusion and conventional treatment. CSII did not significantly restrict the activity of the patients.

Table 1. Clinical features of patients

\begin{tabular}{|c|c|c|c|c|c|c|c|c|}
\hline Case no. & $\begin{array}{l}\text { Age } \\
\text { (years) }\end{array}$ & Sex & $\begin{array}{l}\text { Known duration } \\
\text { of diabetes } \\
\text { (years) }\end{array}$ & $\begin{array}{l}\text { Body } \\
\text { mass } \\
\text { index }\end{array}$ & $\begin{array}{l}\text { Insulin dose o } \\
\text { treatment (un } \\
\text { A. M. }\end{array}$ & $\begin{array}{l}\text { onventional } \\
\text { P. M. }\end{array}$ & $\begin{array}{l}\text { Final daily dose of insulin } \\
\text { infused ( } \% \text { of conven- } \\
\text { tional treatment) }\end{array}$ & $\begin{array}{l}\text { Basal rate } \\
\mathrm{U} / \mathrm{h}\end{array}$ \\
\hline 1 & 20 & M & 10 & 18.6 & Rapitard 64 & & 88 & 1.7 \\
\hline 2 & 53 & M & 18 & 25.3 & Lente 56 & & 78 & 1.3 \\
\hline 3 & 42 & M & 3 & 21.2 & $\begin{array}{l}\text { Monotard } 28 \\
\text { Actrapid } 8\end{array}$ & & 125 & 1.7 \\
\hline 4 & 37 & M & 7 & 27.1 & Soluble 44 & Soluble 20 & 79 & 1.6 \\
\hline 5 & 19 & M & 10 & 22.9 & Rapitard 20 & Rapitard 20 & 150 & 1.8 \\
\hline 6 & 33 & $F$ & 23 & 24.4 & $\begin{array}{l}\text { Soluble } 18 \\
\text { Soluble } 10 \\
\text { (noon) }\end{array}$ & Soluble 12 & 100 & 1.2 \\
\hline
\end{tabular}

\footnotetext{
a Body mass index $=$ weight $(\mathrm{kg}) /$ height $^{2}$ (metres). Mean $\pm \mathrm{SD}$ for normals, $23.9 \pm 3.1$
} 
Table 2. Comparison of plasma glucose and $\mathrm{M}$-values in patients on their conventional regimen and during CSII. Range for $\mathrm{M}$ values in non-diabetics, $0.1-12$

\begin{tabular}{|c|c|c|c|c|c|c|}
\hline \multirow[b]{2}{*}{$\begin{array}{l}\text { Case } \\
\text { no. }\end{array}$} & \multicolumn{3}{|c|}{ Mean plasma glucose (mmol/l) and (range) } & \multicolumn{3}{|c|}{ Mean $M$ value and (range) } \\
\hline & $\begin{array}{l}\text { Conventional } \\
\text { treatment }\end{array}$ & $\begin{array}{l}\text { Final } \\
\text { infusion day }\end{array}$ & $\mathbf{P}$ & $\begin{array}{l}\text { Conventional } \\
\text { treatment }\end{array}$ & $\begin{array}{l}\text { Final } \\
\text { infusion day }\end{array}$ & $\mathbf{P}$ \\
\hline 1 & $\begin{array}{l}14.3 \\
(7.2-21.3)\end{array}$ & $\begin{array}{l}8.2 \\
(2.7-12.2)\end{array}$ & $<0.01$ & $\begin{array}{l}142 \\
\quad(9.4-316)\end{array}$ & $\begin{array}{l}32 \\
(0.02-85)\end{array}$ & $<0.01$ \\
\hline 2 & $\begin{array}{l}12.0 \\
(4.0-18.3)\end{array}$ & $\begin{array}{l}6.0 \\
(4.0-11.1)\end{array}$ & $<0.01$ & $\begin{array}{l}81 \\
(11-233)\end{array}$ & $\begin{array}{l}28 \\
(0.01-63)\end{array}$ & $<0.01$ \\
\hline 3 & $\begin{array}{l}10.9 \\
(4.2-22.4)\end{array}$ & $\begin{array}{l}8.4 \\
(2.3-12.6)\end{array}$ & $<0.02$ & $\begin{array}{l}79 \\
(0.01-348)\end{array}$ & $\begin{array}{l}36 \\
(0.2-94)\end{array}$ & N. S. \\
\hline 4 & $\begin{array}{l}6.1 \\
(0.8-20.3)\end{array}$ & $\begin{array}{l}6.5 \\
(3.1-8.8)\end{array}$ & N.S. & $\begin{array}{l}85 \\
(0.01-433)\end{array}$ & $\begin{array}{l}8.4 \\
(0.2-26)\end{array}$ & $<0.05$ \\
\hline 5 & $\begin{array}{l}13.2 \\
(3.8-27.6)\end{array}$ & $\begin{array}{l}5.5 \\
(2.3-8.3)\end{array}$ & $<0.01$ & $\begin{array}{l}109 \\
(0.04-481)\end{array}$ & $\begin{array}{l}6.5 \\
(0.14-28)\end{array}$ & $<0.01$ \\
\hline 6 & $\begin{array}{l}11.8 \\
(2.2-28.0)\end{array}$ & $\begin{array}{l}12.9 \\
(3.4-25.2)\end{array}$ & N.S. & $\begin{array}{l}125 \\
(0.01-511)\end{array}$ & $\begin{array}{l}129 \\
(0.1-429)\end{array}$ & N.S. \\
\hline
\end{tabular}

At the conclusion of all of the infusion studies the cannula implantation site was inspected and the cannula tips cultured for bacterial growth.

The modified $M$ value of Service et al. [15] was calculated from the formula

$M=\frac{\Sigma\left(10 \log _{10} \frac{B G}{4.44}\right)^{3}}{n}$

where $\mathrm{BG}=$ blood glucose value in $\mathrm{mmol} / \mathrm{l}$ and $\mathrm{n}$ is the number of samples.

Statistical comparisons were by the Wilcoxon test for non-normally distributed data.

\section{Results}

Table 2 shows the mean plasma glucose and $M$ value in patients $1-6$ on their conventional insulin treatment and on the final day of CSII. Because the data was skewed (particularly the $\mathrm{M}$-values) ranges are given. In patients 1-5 the blood glucose control was significantly improved as judged by a reduction in either mean plasma glucose, $M$ value or range of these parameters. In patient 4 the mean plasma glucose was not significantly altered by CSII but the mean on conventional treatment $(6.1 \mathrm{mmol} / 1) \mathrm{con}$ ceals large swings in plasma glucose $(0.8$ to $20.3 \mathrm{mmol} / \mathrm{l})$. The range was lowered to 3.1 to $8.8 \mathrm{mmol} / 1$ by $\mathrm{CSII}$, reflected in a significant reduction in $\mathrm{M}$ value from 85 to 8.4 .

Figure 2 shows the plasma glucose profile of patient 4 during conventional treatment and during CSII. Subcutaneous infusion was started at a basal infusion rate of $2.1 \mathrm{U} / \mathrm{h}(100 \%$ of conventional daily dose when given for 24 hours with 3 high-rate increases). Plasma glucose gradually fell and the patient became symptomatically hypoglycaemic during the night. Accordingly, the infusion dose was changed the next day to $79 \%$ of the control day with a basal rate of $1.6 \mathrm{U} / \mathrm{h}$. There follows 3 days of nearnormoglycaemia at this infusion rate, without biochemical or symptomatic hypoglycaemia.

Patient No. 6 is a "brittle" diabetic, in the sense of suffering unpredictable swings in blood glucose, unrelated to food or exercise. Consequently, her usual dose of insulin is variable, usually three times daily but occasionally four times daily. The dose given in Table 1 is representative. Neither mean plasma glucose, M-value nor their ranges were improved by CSII.

\section{Limits of Control}

The highest plasma glucose recorded during CSII in patients $1-5$ was $12.2 \mathrm{mmol} / 1$. The lowest plasma glucose recorded during CSII was $2.3 \mathrm{mmol} / 1$ but no patient experienced symptomatic hypoglycaemia after the correct infusion dose had been established.

\section{Cannula Implantation Site}

The site at which the nylon cannula was implanted in the subcutaneous tissue was inspected at the conclusion of the experiment. There was no obvious infection or tissue reaction. Culture of the cannula tip proved sterile in every case. 


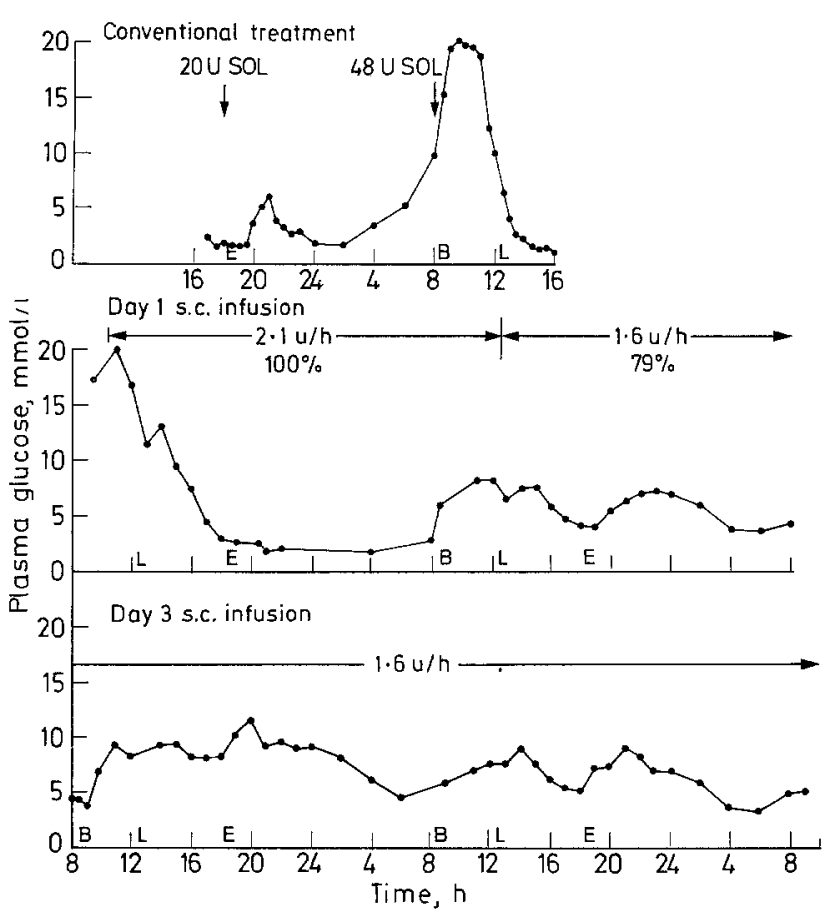

Fig. 2. Plasma glucose profile in patient 4. Upper panel: conventional depot injection treatment of $48 \mathrm{U}$ soluble insulin in the morning and $20 \mathrm{U}$ soluble insulin in the evening. Lower 2 panels: plasma glucose profile during CSII (continuous subcutaneous insulin infusion) for 4 days. CSII was initially at the rate of $2.1 \mathrm{U} / \mathrm{h}$ (basal rate) and after day 1 was altered to $1.6 \mathrm{U} / \mathrm{h}(79 \%$ of the total daily dose on conventional treatment). $\mathrm{B}=$ breakfast, $\mathrm{L}=$ lunch, $\mathrm{E}=$ evening meal

\section{Patient Response}

Worn as an abdominal harness or belt patients found the system reasonably comfortable and unrestricting for ambulant use. The pump was not uncomfortable at night and was worn in the same position as during the day. The slight rhythmical sound of the pump motor quickly became almost unnoticed.

\section{Discussion}

The special requirements demanded from any system aiming at long-term optimal blood glucose control are: freedom from complications at the point of insulin delivery to the body, absence of physical restrictions, applicability to most insulin requiring diabetics and low cost. Continuous subcutaneous insulin infusion appears to fulfil most of these criteria.

A pilot study established that CSII was a feasible means of achieving near-normoglycaemia for 24 hours in some diabetics, $[11,12]$ and the present work has extended and improved good blood glucose control for 4 days. The longer period of study has allowed time to select the optimum infusion dose and schedule and the system appears capable of greatly improving the metabolic control of most diabetic patients.

It is notable that in some patients improved blood glucose control (as assessed by lower mean plasma glucose values and/or less variability about the mean) was achieved using over $20 \%$ less insulin than on the conventional depot injection regime. This emphasises the extent to which control depends upon the distribution of insulin throughout the day and perhaps the avoidance of counter-regulatory swings (Somogyi effect) [16]. A larger proportion of a subcutaneous depot dose may be inactivated by local proteinases than when insulin is continuously infused.

The results obtained in our "brittle" diabetic patient (who had unpredictable swings of blood glucose on the conventional treatment) were disappointing. Control was not significantly improved by CSII and the system may be unsuitable for this rare category of diabetic, at least with the simple regime in current use (high-rate increases before each main meal). The mechanism of brittle diabetes is unknown [16] but it is possible, for example, that insulin absorption from the subcutaneous site may vary in these patients both with CSII and depot injections.

The fact that stable blood glucose control can be maintained by CSII for several consecutive days with the same insulin infusion rate suggests strongly that insulin does not accumulate from day to day at the infusion site, although insulin pharmacokinetic data studies during CSII are not yet available. It is already apparent, however, that hypoglycaemia may not be a particular problem with long-term CSII. This may be due to the fact that with CSII there are never large quantities of insulin within the patient which might overwhelm defective counter regulatory mechanisms.

Diabetics with long-duration of disease (and thus likely to have little remaining endogenous insulin production) in this limited study appeared no more difficult to control with CSII than those of short duration.

To date there has been no infection at the cannula implantation site and this is encouraging for the longterm application of CSII. Even if infection were rarely to occur it may be less hazardous to the patient than its introduction via an intravenous portal.

CSII does not maintain absolute normoglycaemia, as can the artificial pancreas. However, it appears to maintain a degree of blood glucose control in diabetic patients clearly better than most conventional depot regimes. Only a carefully planned trial will tell us if CSII is any better than optimised depot 
regimens (with intensive patient education and selfmonitoring of blood glucose) in achieving metabolic control of diabetes.

Acknowledgements. We thank Sister Pat Johns, the Staff nurses of the Metabolic Ward at Guy's Hospital and Miss Helen Brown, the Ward Dietician, for their help with this study. Mr. K. Kilbourn provided skilful technical assistance and Mr. R. Blows constructed the special dual-rate Mill Hill Infusers. This work was supported by a grant from the British Insulin Manufacturers and KGMMA thanks the British Diabetic Association for support. JCP is also an attached worker at the National Institute for Medical Research, London.

\section{References}

1. Engerman, R., Bloodworth, J. M. B., Nelson, S.: Relationship of microvascular disease in diabetes to metabolic control. Diabetes 26, 760-769 (1977)

2. Job, D., Eschwege, E., Guyot-Argenton, C., Aubry, J. A., Tchobroutsky, G.: Effect of multiple daily insulin injections on the course of diabetic microangiopathy. Diabetes 25, 463-469 (1976)

3. Cahill, G. F., Etzwiler, Freinkel, N.: Blood glucose control and diabetes. Diabetes 25, 237-239 (1976)

4. Siperstein, M. D., Foster, D. W., Knowles, H. C., Levine, R., Madison, L. L., Roth, J.: Control of blood glucose and diabetic vascular disease. N. Engl. J. Med. 296, 1060-1062 (1977)

5. Ingelfinger, F. J.: Debates on diabetes. N. Engl. J. Med. 296, 1228-1230 (1977)

6. Albisser, A.M., Leibel, B.S.: The artificial pancreas. Clin. Endocrinol. Metab. 6, 457-479 (1977)

7. Slama, G., Hautcouverture, M., Assan, R., Tchobroutsky, G.: One to five days of continuous insulin infusion on seven diabetic patients. Diabetes 23, 732-738 (1974)

8. Deckert, T., Lørup, B.: Regulation of brittle diabetes by a preplanned infusion programme. Diabetologia 12, 573-579 (1976)
9. Genuth, S., Martin, P.: Control of hyperglycaemia in adult diabetics by pulsed insulin delivery. Diabetes 26, 571-581 (1977)

10. Renner, R., Hepp, K. D., Mehnert, H., Franetski, M., Kresse, H., Griesen, K.: Continuous insulin therapy with a portable miniaturized infusion system. Diabetologia 13, 427 (Abstract) (1977)

11. Pickup, J. C., Keen, H., Parsons, J. A., Alberti, K. G. M. M. The use of continuous subcutaneous insulin infusion to achieve normoglycaemia in diabetic patients. Diabetologia 13, 425 (Abstract) (1977)

12. Pickup, J. C., Keen, H., Parsons, J. A., Alberti, K. G. M. M.: Continuous subcutaneous insulin infusion: an approach to achieving normoglycaemia. Br. Med. J. 1978 I, 204-207

13. Pickup, J. C., Keen, H., Parsons, J. A., Alberti, K. G. M. M.: Continuous subcutaneous insulin infusion: prolongation of control and correction of intermediary metabolites. Diabetologia 14, 261 (Abstract) (1978)

14. Parsons, J. A., Rothwell, D., Sharpe, J.E.: A miniature syringe pump for continuous administration of drugs and hormones: the Mill Hill Infuser. Lancet 1977 I, 77-78

15. Service, F. J., Molnar, G. D., Rosevear, J. W., Ackerman, E., Gatewood, L. C., Taylor, W. F.: Mean amplitude of glycaemic excursions, a measure of diabetic instability. Diabetes 19 , 644-655 (1970)

16. Tattersall, R. B.: Brittle diabetes. Clin. Endocrinol. Metab. 6, 403-419 (1977)

Received: October 5, 1978, and in revised form: January 3, 1979

Dr. J. C. Pickup

Unit for Metabolic Medicine

Guy's Hospital Medical School

London, SE1 9RT

England 